\title{
Calcitonin and Parathyrin are Glucoregulating Hormones
}

\section{Moisa SS $^{* 1}$ andNozdrachev $\mathrm{AD}^{2}$}

${ }^{1}$ Federal State-Financed Establishment of Science, State Scientific Center of The Russian Federation, Institute of Biomedical Problems of the Russian Academy of Sciences, Moscow, Russia

${ }^{2}$ Institute of Physiology Named by I.P. Pavlov of the Russian Academy of Sciences, St.-Petersburg, Russia

*Corresponding author:Moisa SS,Federal State-Financed Establishment of Science, State Scientific Center of the Russian Federation, Institute of Biomedical Problems of the Russian Academy of Sciences, Moscow, Russia, E-mail: butalana07@list.ru

Received date: December 13, 2013; Accepted date: February 25, 2014; Published date: March 3, 2014

Copyright: $@ 2014$ Moisa SS, et al. This is an open-access article distributed under the terms of the Creative Commons Attribution License, which permits unrestricted use, distribution, and reproduction in any medium, provided the original author and source are credited.

\begin{abstract}
The comprehensive literature data and our findings about calcium-regulating hormones participant in the glucose metabolism is analyzed. It is showed calcitonin hyperglycemic effect and its mechanisms, established contra-insulin effect of calcitonin to insulin under the pre-receptor, cell level and liver. It is ascertained the impairment of glucose metabolism under calcitonin - hyperglycemia, insulin resistance and glucose intolerance. It is showed the data of combinative effect of calcitonin and calcium antagonists on glucose metabolism. It is discussed calcitonindiabetogeniceffect and the role of calcium antagonists in the correction of hyperglycemia and tissue's insulin resistance. It was revealed the effect of parathyrin on glucose, occurring in decreasing the glucose level and increases glucose tolerance. It is concluded about participant of calcium-regulating hormones in theregulation of glucose metabolism.
\end{abstract}

Keywords: Calcitonin; Parathyrin; Insulin; Glucose metabolism; Glucose tolerance; Glucoregulating hormone

\section{Introduction}

Calcitonin (CT) and parathyrin (PTH) are widely used in medical practice not only for the treatment of bone system diseases but for the treatment of a number of inner organs [1-7]. In case of it their possible effect on endocrine system, in part, carbohydrate metabolism, doesn't take into account. In this connection on the basis of our data and comprehensive literature data the effect of calcium-regulating hormones on glucose metabolism was considered.

\section{Calcitonin is a Stress Component}

Intensification of CT secretion marks not only under the primary alterations of calcium metabolism, but and under some agents, not effecting immediate on calcium depot and the target-cells of hormone, for example, under stress-situations: under immobilizing stress in rats [8-10], childbirth [10], experimental muscle load (running on the treadmill) and in men's serum, carrying out some muscle load on veloergometer $[9,11,12]$, attacks of bronchial asthma [10], insulin hypoglycemia [13], alcohol influence [14]. Recently it was shown the intensification of pro-CT under the stress (multiple traumas) [15]. It is supposed that CT and low calcium level limit stress activation of hypothalamus-hypophysis-adrenal system and the expression of generaladaptationsyndrome and, that $\mathrm{CT}$ is a humoral component of stress [16]. The increasing of CT secretion and hypocalcaemia evoked by it promote to limiting the stress-reaction. Besides that, a significant increasing of CT level and decreasing of calcemia arises only under the long stress [16]. In this opinion it should appreciate the increasing level of CT under the primary revealing manifest diabetes in man [17]. Presence of specific and non-specific organs and tissues, which CT occurs the effect causes its effects and allows consider it as a hormone of a wide spectrum action. In the present it is known non-metabolic: analgesic [18], vasodilating, hypotensive [19] and metabolic: anorexic and hyperglycemic effect of CT [20-23].

\section{Calcitonin and Glucose Metabolism}

It is well-known now the hyperglycemic effect of the preparations of salmon, pig CT [24,25] and CT-gene-related peptide [19]. Under onetime injection of exogenous CT (the preparation ofpigCT-calcitrin) was revealed an expressive hypocalcemic and hyperglycemic effect in rats of all age groups, that testifies about the existence of the correlation between the neuro-endocrine regulation of calcium metabolism and the functional state of pancreas islet's apparatus, which expression has some aging peculiarities. There are functional (immature, $\mathrm{r}=-0,917, \mathrm{P}<0,01$ ), close (adult, $\mathrm{r}=-0,834, \mathrm{P}<0,02$ ) and expressive (old rats, $\mathrm{r}=-0,581, \mathrm{P}<0,05$ ) negative correlation was established between glucose and calcium level.

It is obviously, that the degree of hyperglycemia after one-time injection of CT in the rats of all age groups depended on the functional state of its islet's apparatus [21]. The investigation of CT effect on the dynamics of glycemia evoked glucose load per osin the rats of different age and sex groups also revealed the reliable increasing of initial blood glucose level and glucose intolerance, moreover, the males occurred more sensitive to this hormone action than the females [22]. It is established that CT didn't effect on the glucose absorption in small intestine, but influenced on the main stages of the intermediate metabolism, intensifying the glycogenolisis and insulin resistance of the peripheral tissues [26]. CT decreased insulin-stimulated glucose consumption by muscle and adipose tissue in vivo and in vitro [27].

In our previous investigations in rats $[28,29]$ it was shown, that CT didn't effect on initial insulin level, but slowed down it secretion under glucose-tolerance test, i.e., it is originated as though delaying of secret reaction of $\beta$-cells. Mechanism of CT effect on insulin secretion remains to be unknown. Possibly, hypocalcaemia, CT-evoked, leads to the decreasing of intracellular calcium concentration in B-cells cytozol, 
what, evidently, inhibit the leaving of secret granules and come to the delaying of insulin secretion. Moreover, it must be taken into account that CT leads to the decreasing of muscle and adipose tissue sensitivity to insulin [27]. In respect of CT effect on the glucagons level were received data about the decreasing of initial level and increasing its level under insulin hypoglycemia in rats [28]. Analogues data were marked and under inspection healthy persons and patients withinsulin-depended diabetes [30]. Mechanism of inhibitory CT effect on glucagons secretion is unknownyet. Possible, CT effect is depended on the stimulation of $\mathrm{Ca}^{2+}$ leaving from $a$-cells and intercellular translocation of $\mathrm{Ca}^{2+}[31]$. The intensifying of glucagons secretion, induced CT, under insulin hypoglycemia, apparently, connected with hypocalcaemia, as far as it is established that the decreasing of $\mathrm{Ca}^{2+}$ concentration leads to the increasing of glucagons removal from $\alpha$-cells [32]. Further investigations will show, whether the increasing glucagons secretion, CT-induced against the background of hypoglycemia, take part in the realization of its diabetogenic action.

Mechanism of hyperglycemic effect of the preparations of CT is studied not enough. The results of our previous investigations allow consider that it is mediated both due to the inhibitory effect of CT on insulin secretion $[28,29]$, the decreasing of glucose consumption by peripheral tissues [27] and due to the intensification of glycogenolysis process [26,33]. The interest to mechanisms of CT effect is explained also by the search of some means of management by this most important bio-regulator. The inhibition by calcium channel blockers (isoptin and nifedipin) hyperglycemic CT effect testifies about the participant of slow potential-depended L-type and chemo-sensitive calcium channels in this effect of hormone $[34,35]$ and gives the basis to consider that calcium channel blockers therapy can be the method of correction of hyperglycemia and insulin-resistance of tissues [36]. Moreover, it is known that calcium channel blockers affect also other components of the metabolic syndrome, revealing athero-protective [37-39], hypotensive [40], lipolitic [41,42], anti-anginal, neuroprotective action. It is shown that potential-managed ion channels are effective target of cyto-pharmacological regulation of functional state [43]. On the basis of this data the concept of directed effect at $\mathrm{Ca}^{2+}$ mechanisms of endocrine system as possible way of drug therapy is formed lately.

\section{Contra-Insulin Effect of Calcitonin}

As gearing data testify CT reveals anti-insulin effect on glucose metabolism [44,45]. It is known, insulin antagonists are the subjects which are capable or direct inhibit insulin action or destroy its molecule or affect the contrary of insulin the metabolic effect. From these conceptions, the antagonism of CT effect to insulin is established concerning to tissues-target for insulin: liver, muscle and adipose tissue. It is known, that the disturbance of glucose homeostasis can arise on the pre-receptor (the alteration of the structure and function of pancreas and/or insulin), cell level (the disturbance of the sensitivity to insulin of adipose and muscle tissue) and on theliver level (the increasing of glucose production) [46]. Therefore, CT provides the opposite action to insulin effect on glucose homeostasis on the prereceptor level (inhibits secretion and biological insulin effect), on cell level (decreases the sensitivity to insulin of muscle and adipose tissue) and on the liver level (intensifies glycogenolysis and glyconeogenesis) and hyperglycemia, insulin-resistance and glucose intolerance are as the result. As it is known, glucose intolerance under glucose-tolerance test is one of clinical symptoms of insulin-resistance. In accordance with the concept of Reaven [47], insulin resistance is a basic component of the metabolic syndrome [46], along with obesity, arterial hypertension, dyslipidemia (elevated triglycerides and low high-density lipoprotein cholesterol), and impared glucose metabolism (high fasting glucose, impaired glucose tolerance). The progression of the metabolic syndrome leads to the development of prediabetes, diabetes, cardiovascular disease, nonalcoholic fatty liver disease, gout, syndrome of hyperandrogenism (polycystic ovaries) and cancer. According to some authors [48], decreased tissue sensitivity to insulin is an important link in the pathogenesis of diabetes, and factors, causing a decline in insulin sensitivity, can be considered as risk factors for the incidence of diabetes. So, in our opinion, one can suppose, that concerning to glucose CT under definite conditions can be as a 'risk factor' of the development of the metabolic syndrome and diabetes mellitus. The analysis about the antagonistic effect of CT concerning to insulin allow think it is a contra-insulin hormone and suppose about its diabetogenic action.

\section{DiabetogenicEffectof Calcitonin}

There is no single opinion about CT diabetogenic effect inliteraturedata, but fact data are rather contradictory [49,50]. Clinical observations for the patients with Paget's disease and a long-time CT treatment are not identical. Gattereauet al. [50] describe the hyperglycemic effect of synthetic salmon CT and the existence of a strong reverse correlation between plasma calcium level and glucose level, and others [49] didn't reveal the symptoms of diabetes mellitus in patients with Paget's disease even after 8 years of CT treatment. These data allow suppose that diabetic effect of CT reveals not always, but, apparently, under the changing of the initial state of pancreas $\beta$ cells, especially under their intensive activity. It is admitted suppose that CT, long-lasting high concentration in blood, and especially under unfavorable conditions (obesity, age, aggravating heredity et al.) can act on insulin receptors indirect due to the metabolic processes and induce the development of the relative insulin deficiency caused by the decreasing of its biological activity. In our investigations it was shown glucose intolerance in children with the $1^{\text {st }}$ degree obesity [25] and also more expressive glucose intolerance in adult and old rats under glucose tolerance test against the background of CT injection [22].

One should mean and the circumstancethat under the chronicincreasing of CT content in blood (both as a result of the treatment of this hormone and in case of CT-produced tumors) organs-target adapted to CT and stop to react on it. Concerning to $\beta$ cells it means that they stop to answer by disturbance of its function on the increasing CT level in serum. But this adaptation is reverse: after the break of CT treatment the initial reaction of organ-target to this hormone restores [51].

Besides, the increasing secretion of CT occurs in stress situations, in this connection hypercalcitoninemia arises [52]. In these conditions endogenous CT can make the same effect on the regulation of carbohydrate metabolism as exogenous injections of hormone.

\section{Parathyrinand Glucose Metabolism}

A number of investigations are showed that PTHactivates $\mathrm{Ca} 2+$ entering in the cells of organs, not being its direct targets. PTHeffect on glucose metabolism practically is unstudied. The single information about the increasing of PTHlevel in blood serum under diabetes mellitus [17] and the metabolic syndrome [53] is available. 
Moreover, it is established the increasing of $\mathrm{Ca}$ and $\mathrm{P}$ excretion with urine under the metabolic syndrome, what positively correlated with the glycemia and the insulin level in blood [53] and the intensification of bone resorption, that it is connected with the disturbance of $\mathrm{Ca}-\mathrm{P}$ metabolism and the secretion of calcium-regulating hormones [54]. On the other hand, the disturbances of carbohydrate and lipid metabolism were revealed under the primary hyperparathyriosis [55].

There are some data about the stimulating effect of hypercalcaemia, induced by introducing of Ca-salts, which improved the assimilation of intra-vein glucose injection and increased the concentration of immunoreactive serum insulin [56]. It allowed suppose about the presence of PTHeffect on the islet's apparatus of pancreas.

It was showed the decreasing of the blood glucose level after onetime injection of parathyroidin (the preparation of bull PTH), which caused by hypercalcaemia, that confirms in tests with the calcium laktat load [57]. Besides, there is a close negative correlation established between glucose and calcium level $(\mathrm{r}=-0,813, \mathrm{P}>0,02)$.

It is known that hypercalcaemia induces the increasing of insulin secretion $[58,59]$. Thereby, a special interest is the data about the decreasing of initial glucose level and the dynamics of alimentary hyperglycemia after PTH injection. Unlike CT, induced glucose intolerance, $\mathrm{PTH}$, on the contrary, decreasing the blood glucose level, decreased the degree of hyperglycemia, i.e. it increased glucose tolerance [57]. Apparently, PTHdue to hypercalcaemia stimulates insulin secretion, which, in one's turn, normalizes the blood glucose level and the same one doesn't make worse glucose tolerance. Analogues data were received under acute hypercalcaemia [60].

Calcium channels blockers (isoptin and nifedipin) led to much more decreasing of hyperglycemia under glucose-tolerance test against the background of PTH [57]. It indicates the role of L-type $\mathrm{Ca}^{+}$channel in the mechanisms of PTH effect on glucose homeostasis and testifies about PTHcapacity to increase glucose tolerance.

A special interest is the data of glucose consumption by muscle and adipose tissue in vivo and in vitro. Just like CT, PTHdidn't effect on glucose consumption by these tissues but unlike CT [27] it didn't change insulin-stimulating effect on this process [57].

Thus, it is established the opposite to CT action of PTHon glucose metabolism. In this connection, it is acceptable to consider, that PTHis CT antagonist not onlyconcerning to the regulation of calcium metabolism, but and glucose metabolism. So, it can take into consideration, that PTHtakes part in neuro-endocrine regulation of carbohydrate metabolism being CT antagonist, i.e. PTHas CT [61,23] is a gluco-regulating hormone.

\section{Correlation of calcium and glucose metabolism}

It is rather interesting to note that such glucose-increasing hormones as glucagons, ACTH, STH, gluco-corticoids, thyroxin also occur and hypocalcaemic effect, i.e. as CT they take part in the regulation of calcium and glucose metabolism, that is an additional confirmation of the functional correlation of calcium and carbohydrate metabolism.

The establishment of a functional negative correlation between glucose level and the total calcium content after CT and PTH injections testifies about the close interconnection of calcium and glucose metabolism. With respect to interconnection of calciumregulating hormones and its effect on glucose and calcium metabolism it can consider that under in vivo the effects of CT and PTHcan be, in the known degree, the result of changing of circulating $\mathrm{Ca}^{2+}$, in vitroindeed they must consider as the result of direct hormone effect. In other words, in the different cells not having a specialized receptors of CT and PTH occur $\mathrm{Ca}^{2+}$-dependent processes subordinated its regulating effects.

Concerning to inter-correlation of the effects of calcium-regulating hormones on glucose metabolism one can suppose that, under hypercalcitoninemia and, correspondently, hypocalcaemia, PTHsecretionintensifies, which, in one's turn, increases calcium level in blood serum, consequence of it there is the increasing of insulin secretion by pancreas $\beta$-cells. It is established, that hypercalcemia [59] and the increasing of intercellular $\mathrm{Ca}^{2+}$ concentration take the important role in insulin secretion by pancreas $\beta$-cells [58]. CT, however, inhibits insulin secretion [28,29]. In addition, CT increases glucagons secretion, apparently, as it is mentioned above, due to the decreasing of the total calcium content in blood serum.Apparently, by this way a reciprocal interrelations between CT and PTHsecretion and their effect on glucose and calcium metabolism occur, which reveals due to their modulating effect on insulin and glucagon secretion. Therefore, PTH acts as insulin agonist and CT- as antagonist. $\uparrow$ calcitonin level $\rightarrow$ Hypocalcemia $\rightarrow \downarrow$ Insulin secretion $\rightarrow$ Hyperglycemia

$$
\downarrow
$$

$\uparrow$ Parathormone secretion $\rightarrow$ Hypercalcemia $\rightarrow \uparrow$ Insulin secretion

$$
\downarrow
$$

Hypoglycemia

Glucosa, calcium, $\beta$-cells function and calcium-regulating hormones are connected between them by feedback mechanisms [62].Beyond all doubt, neuro-endocrine mechanisms of their interconnection require the further investigation. However, findings on this stage enlarge the conceptions about physiological role of CT and PTH, testify about the involving of $\mathrm{Ca}^{2+}$-mechanisms and give the basis to consider them as the important modulators of secret and metabolic processes.

\section{References}

1. Vik A, Yatham LN (1998) Calcitonin and bipolar disorder: a hypothesis revisited. J Psychiatry Neurosci 23: 109-117.

2. Wall GC1, Heyneman CA (1999) Calcitonin in phantom limb pain. Ann Pharmacother 33: 499-501.

3. Chesnut $\mathrm{CH}$, Silverman S, Andriano K, Genant H, Gimona A, et al. (2000) A randomized trial of nasal spray salmon calcitonin in postmenopausal women with established osteoporosis: the prevent recurrence of osteoporotic fractures study. PROOF Study Group. Am J Med 109: 267-276.

4. Lee M, Kim BJ, Lim EJ, Back SK, Lee JH, et al. (2009) Complete Freund's adjuvant-induced intervertebral discitis as an animal model for discogenic low back pain. AnesthAnalg 109: 1287-1296.

5. Villa A, Guerrini MM, Cassani B, Pangrazio A, Sobacchi C (2009) Infantile malignant, autosomal recessive osteopetrosis: the rich and the poor. Calcif Tissue Int 84: 1-12.

6. Villalón CM, Olesen J (2009) The role of CGRP in the pathophysiology of migraine and efficacy of CGRP receptor antagonists as acute antimigraine drugs. PharmacolTher 124: 309-323.

7. Cesareo R, Napolitano C, Iozzino M, Romitelli F, Iarussi G, et al. (2009) Using parathyroid hormone 1-84 in the treatment of osteoporosis: presentation and comments of main clinical trial. ClinTer 160: 307-310.

8. Drzhevetskaia IA, Mishina NF (1978) Participation of thyrocalcitonin in the development of stress. FiziolZh SSSR Im I M Sechenova 64: 864-868. 
9. Drzhevetskaja IA, Mishina NF, Limanskii NN (1978) Thyrocalcitonin is a stress component. Materials of the 5th meeting on the problem "Hystogematic barriers", dedicated to 100 -anniversary of the academician L.S. Shtern. Moscow 350-351.

10. Mishina NF (1981) Calcitonin participant in stress development in postnatal ontogenesis. Autoreferat diss. Candidate of Sciences (Medicine). Leningrad. Institute of Physiology named by I.P.Pavlov of Russian Academy of Sciences. 19 P.

11. Drzhevetskaia IA, LimanskiÄ NN (1978) Plasma thyrocalcitonin activity and calcium levels during muscular activity. FiziolZh SSSR Im I M Sechenova 64: 1498-1500.

12. Limanskii NN (1981) Correlation of calcitonin and hormones of hypothalamo-hypophizarno-adrenocortical system under the muscle activity. Autoreferat diss. Candidate of Sciences (Biology). Moscow. Moscow State Pedagogical Institute. 16 P.

13. Butakova (Moisa) SS, Nozdrachev AD (2010) Physiological mechanisms of calcitonin secretion under insulin hypoglycemia. Vestnik S-Petersburg Uneversity 3: 100-106.

14. Drzhevetskaja IA, Mishina, NF, Limanskii NN et al. (1983) Physiological role of calcitonin. Materials of XIV Congress of All-Union Physiological Society named by I.P. Pavlov. Baku. Leningrad department "Nauka". Leningrad 1:244.

15. Fei, Jun, Yu, Hong-jun, Zhou, Jian et al. (2005) The alterations of procalcitonin content in blood serum of patients with multiple traumas. Clin. J. Trauma. 21. 10. 725-728.

16. Drzhevetskaja IA, Drzhevetskii, Yu M (1983) Hormonal regulation of calcium metabolism and secret processes. The totals of science and technic. Seria "Physiology of Human and Animals". Moscow 27: 132

17. Mosin VI, Iagoda AV, Grossman BE (1980) Blood levels of parathyroid hormone, calcitonin and cyclic adenosine monophosphate in diabetes mellitus. TerArkh 52: 80-83.

18. Butakov(Moisa)SS, IgnatovIuD (1996) The effect of calcium-regulating hormones on pain sensitivity in rats. EkspKlinFarmakol 59: 9-11.

19. Moore MC, Lin DW, Colburn CA, Goldstein RE, Neal DW, et al. (1999) Insulin- and glucagon-independent effects of calcitonin gene-related peptide in the conscious dog. Metabolism 48: 603-610.

20. Yamaguchi M, Yamamoto T (1977) Effect of calcitonin on serum glucose concentration in rats. Chem Pharm Bull (Tokyo) 25: 2189-2194.

21. Butakova(Moisa)SS, Nozdrachev AD (2010) Effect of one-time injection of calcitonin preparations on glucose and calcium level in rats of different age groups. AdvGerontol 23: 93-97.

22. Butakova(Moisa)SS, Nozdrachev AD (2010) Effect of calcitonin on the type of alimentary hyperglycemia in rats of different age and sex. AdvGerontol 23: 213-220.

23. Moisa SS, Nozdrachev AD (2011) Mechanisms of calcium and carbohydrate metabolism regulation (Monograph) LAP LAMBERT Academic Publishing GmbH \&Co. 319 P.

24. Yamaguchi M, Yamamoto T (1977) Effects of insulin and calcitonin on the levels of serum calcium and glucose in rats. Chem Pharm Bull (Tokyo) 25: 2785-2787.

25. Moisa SS, Nozdrachev AD (2013) One-time injection of calcitonin induces glucose intolerance in children with the 1st degree obesity. Health (USA). 5:9-13.

26. Butakova (Moisa) SS, Nozdrachev AD (2011) Mechanisms of Hyperglycemic Effect of Calcitonin. Bull ExpBiol Med 150: 320-323.

27. Butakova(Moisa)SS, Nozdrachev AD (2009) Effect of calcium-regulating hormones and calcium channel modulators on glucose consumption by muscle and adipose tissues in vivo and in vitro. Bull ExpBiol Med 148: 171-174.

28. IaroshevskiiYuA, DarinskiiYuA, Butakova(Moisa)SS (1989) Effect of calcitonin on insulin and glucagon secretion by the pancreas. ProblEndokrinol (Mosk) 35: 58-61.

29. Butakova (Moisa) SS (2008) Calcitonin, a modulater of pancreas secret process. Mechanisms of functioning of visceral systems: VI All-Russian Conf. with international participant devoted to the 50-th anniversary of discovery of membrane digestion by A.M. Ugolev. Thesis of addresses. Saint-Petersburg. Institute of Physiology named by I.P. Pavlov of The Russian Academy of Scienses. 26-27.

30. Starke A, Keck E, Berger M, Zimmermann H (1981) Effects of calcium and calcitonin on circulating levels of glucagon and glucose in diabetes mellitus. Diabetologia 20: 547-552.

31. Petralito A, Lunetta M, Liuzzo A, Fiore CE, Heynen G (1979) Effects of salmon calcitonin on blood glucose and insulin levels under basal conditions and after intravenous glucose load. J Endocrinol Invest 2: 209-211.

32. Panzig E, Besch W, Rosenbaum KD, Tietz W, Kiene S, et al. (1985) The effect of potassium, calcium and magnesium concentration on insulin and glucagon secretion of the perfused dog pancreas. ExpClinEndocrinol 86: 61-68.

33. Yamaguchi M (1981) Calcitonin stimulates gluconeogenesis in fasted rats. EndocrinolJpn 28: 51-57.

34. Butakova (Moisa) SS,Nozdrachev AD (2010) Calcium channel blockers: the correction method of hyperglycemia and insulin-resistance, induced by calcitonin. Materials of I All-Russian science-practical conference "High Technology, fundamental and applied researches in medicine and physiology". Saint-Petertsburg. 2: 79-81.

35. Butakova(Moisa)SS, Nozdrachev AD (2012) Calcium channel blockers inhibit the hyperglycemic effect of calcitonin. Bull ExpBiol Med 152: 553-559.

36. McCarty MF (2006) PKC-mediated modulation of L-type calcium channels may contribute to fat-induced insulin resistance. Med Hypotheses 66: 824-831.

37. Orekhov AN, Baldenkov GN, Tertov VV, RudaMYa, Khashimov KA, et al. (1990) Antiatherosclerotic effects of calcium antagonists. Study in human aortic cell culture. Herz 15: 139-145.

38. Hernández RH, Armas-Hernández MJ, Velasco M, Israili ZH, ArmasPadilla MC (2003) Calcium antagonists and atherosclerosis protection in hypertension. Am J Ther 10: 409-414.

39. Mason RP (2003) Atheroprotective effects of long-acting dihydropyridine-type calcium channel blockers: evidence from clinical trials and basic scientific research. Cerebrovasc Dis 16 Suppl 3: 11-17.

40. Shilova EV, Marcevich, Yu C (2008) Dihydropiridine calcium antagonists: a role in modern therapy of cardio-vascular diseases. Rational Pharmacother 2: 53-57.

41. Wilkinson WO, Zemel MB, Naima MM (2003) Modulation of the sulfonylurea receptor and calcium in adipocyties for treatment of obesity/ diabetes. Artesel Science Inc.

42. Zanos S, Mitsopoulos E, Sakellariou G (2005) Parathyroid hormone levels, calcium-channel blockers, and the dyslipidemia of nondiabetic hemodialysis patients. Ren Fail 27: 163-169.

43. Vislobokov AI (2001) Membrane mechanisms of the action of pharmacological preparations of different groups on neuron cells. Authoreferat diss. Doctor of Sciences (Biology). Saint-Petersburg. SaintPetersburg Medical University named by academician IP Pavlov.

44. Butakova (Moisa) SS, Nozdrachev AD (2010) Calcitonin--contra-insulin hormone. AdvGerontol 23: 364-370.

45. Moisa SS (2013) Contra-insular effect of calcitonin on glucose metabolism. Bull ExpBiol Med 156: 217-219.

46. Metabolic syndrome (2007) EdRoitberg GE. Moscow 223 P.

47. Reaven G (2004) The metabolic syndrome or the insulin resistance syndrome? Different names, different concepts, and different goals. EndocrinolMetabClin North Am 33: 283-303.

48. Baranov VG, IaroshevskiiYuA (1980) Relative insulin deficiency as a primary factor in pathogenesis of spontaneous diabetes mellitus. ProblEndokrinol (Mosk) 26: 3-8.

49. Freed WJ, Perlow MJ, Wyatt RJ (1979) Calcitonin: inhibitory effect on eating in rats. Science 206: 850-852.

50. Gattereau A, Bielmann P, Durivage J, Larochelle P (1977) Hyperglycaemic effect of synthetic salmon calcitonin. Lancet 2: 1076-1077. 
Citation: Moisa SS, Nozdrachev AD (2014) Calcitonin and Parathyrin are Glucoregulating Hormones. J Mol Genet Med S1: 024. doi: 10.4172/1747-0862.S1-024

Page 5 of 5

51. Ziegler R (1983) Calcitonin and the endocrine pancreas. Triangle 22: 2-3.

52. Drzhevetskaja IA, Mishina NF, Limanskii NN (1982) Secretion and functional reserves of calcitonin in man. Neuroendocrine mechanisms of adaptation. Stavropol.

53. Belych OA, Geltser BI, Kochetkova EA (2006) Condition of Ca-P metabolism in young women with metabolic syndrome. Far-East Med J.

54. Belych OA (2006) Functional metabolic mechanisms of remodelizing of bone tissue in young women with dishormonalpatholohy. Amursk State Medical Academy.

55. Voronenko IV, Mokrysheva, NG, Rozhinskaja, LYa(2008) Disturbances of carbohydrate and lipid metabolism under the primeryhyperthyriosis. Obesmetab. 4. 18-24.

56. Kakita K, Kakita S (1985) Analysis of immunoreactiveinsulins in man in relation to the effects of aging. Biochem Med 34: 176-181.

57. Moisa SS, Nozdrachev AD (2013) One-time injection of parathyrin increases glucose tolerance. Open J EndocrMetabDis 3: 293-300.
58. Kim HS, Yumkham S, Lee HY, Cho JH, Kim MH, et al. (2005) Cterminal part of AgRP stimulates insulin secretion through calcium release in pancreatic beta Rin $5 \mathrm{mf}$ cells. Neuropeptides 39: 385-393.

59. Parthemore JG, Deftos LJ (1978) Calcitonin secretion in normal human subjects. J ClinEndocrinolMetab 47: 184-188.

60. Gedik O, Akalin S, Koray Z (1980) Effect of acute hypercalcaemia on glucose tolerance and insulin release in human beings. ActaEndocrinol (Copenh) 94: 196-200.

61. Butakova (Moisa) SS, Nozdrachev AD (2010) Calcitonin glucoregulating hormone. Vestnik Of Russian Military Medical Academy 4:188-196.

62. Zoloev GK, Slepushkin VD, Yakovleva RA (1984) Relationships between the two-valencycationes, the function of the insular apparatus of pancreas and calcium-regulating hormones under the alteration of blood glucose level. Human Physiol 10:450-453.
This article was originally published in a special issue, entitled: "Molecular and Cellular Aspects in Obesity and Diabetes", Edited by Dr. Masayoshi

Yamaguchi, Emory University School of Medicine, USA 